\title{
Sociodemographic Predictors of Genital Mutilation (Circumcision) of the Girl Child in Nigeria: A Population-Based Study
}

\author{
Donatus Ignatius Chidiebere Osuorah ${ }^{1,2^{*}}$
}

\begin{abstract}
Objectives: Female circumcision is regarded as mutilation of the external genitalia of women and the girl child. It is entrenched in the cultures of many communities in developing countries particularly in Africa. It has long been recognized internationally as a violation of the right of the woman and the girl child.

Materials and Methods: This study tried to determine the sociodemographic factors that predict circumcision of the girl child. Multivariate logistic regression was used to determine predictors of girl child circumcision.

Results: The overall prevalence of the girl child circumcision in Nigeria is $23.9 \%$. When stratified by region, the prevalence was $36.8 \%, 15.6 \%$, and $9.1 \%$ in the North-west, North-central and North-east region, respectively and $30.8 \%, 22.8 \%$, and $8.0 \%$ in the South-west, South-east and South-south region, respectively. Within states, the prevalence of female circumcision ranged from $0 \%$ in Katsina to $57.9 \%$ in Jigawa state. Prevalence was almost twice among Muslim households than other religions. Majority (91.8\%) of the girl child circumcision was done before the first birthday (0-11 months) and $84.6 \%$ was performed by a traditional circumciser. Type I (44.1\%) and II (47.9\%) were the commonest type of genital mutilation performed. In the final regression model, only mothers opinion about female circumcision, whether she was circumcised and region of residence significantly determined the likelihood of a girl child been circumcised.

Conclusion: Appropriate and targeted education of mothers and circumcisers focusing on the undesirable effect of female circumcision will significantly reduce the practice of female genital mutilation (FGM) across Nigeria.

Keywords: Child, Circumcision, Female, Genital mutilation, Nigeria
\end{abstract}

\section{Introduction}

Female circumcision also referred to as female genital cutting (FGC) or female genital mutilation (FGM), includes all surgical procedures involving partial or total removal of the external genitalia or other injuries to the female genital organs for cultural or other nontherapeutic reasons (1). It is one of the most serious forms of violence against the girl child and women. Many reasons based on erroneous belief have been proffered by different community and culture to justify this social menace. They include but not limited to helping women reduce their sexual desires in order to maintain chastity and virginity before marriage and faithfulness during marriage, identification with cultural heritage and initiation of girls into womanhood. Others include religious requirements, to promote hygiene and provide aesthetic appeal, proper social integration, etc (1).

Globally an estimated 100 to 140 million girls and women have undergone genital mutilation and in Africa alone more than 3 million girls are at risk of genital mutilation every year (2). Many adverse health and reproductive complications has been attributed to the practice of FGM. According to a World Health Organization (WHO) study in 2006, female circumcision can lead to increased risk for health conditions such as severe pain, hemorrhages, tetanus and/or other infections, infertility, psychological and/ or sexual problems, abscesses and/or cysts, urinary incontinence, obstruction during childbirth and even maternal deaths (3). Even worse is the fact that the complications arising from circumcision are usually concealed by victims and/or their family for fear of being labeled societal outcast by the community thus perpetuating the circle of this atrocious act against women and the girl child (4).

Extensive review of literatures showed no study has specifically looked into FGM of the girl child in Nigeria. It is believed that studies to determine the various factors that influence female circumcision across countries and within cultures will help inform targeted policies and intervention to reduce the practice of FGM. This study therefore seeks to determine the prevalence and practice of FGM and further probe into sociodemographic factors that influence the practice of genital mutilation among the girl

Received 5 December 2014, Accepted 2 April 2015, Available online 1 July 2015

${ }^{1}$ Child Survival Unit, Medical Research Council Unit, The Gambia. ${ }^{2}$ Department of Pediatrics, Nnamdi Azikiwe University Teaching Hospital, Nnewi, Anambra, Nigeria.

*Corresponding author: Donatus Ignatius Chidiebere Osuorah, Care of Medical Research Council Unit, 78 Atlantic Boulevard Fajara The Gambia. Tel: +2348104818886, Email: chidi.osuorah@yahoo.com 
child in Nigeria.

\section{Materials and Methods \\ Study Area}

Nigeria is in West African subregion divided into 36 states and a Federal Capital Territory. These states are situated in 6 geopolitical regions: North-west, North-east, North-central, South-west, South-east and South-south (5). There are 774 constitutionally recognized local government areas and more than 374 identifiable ethnic groups within these states and regions (5).

\section{Sample Design}

The sample for the 2013 Nigeria Demographic and Health Survey (NDHS) is a nationally representative one. It covers the entire population residing in non institutional dwelling units throughout the country. The survey used Enumeration Areas (EAs) provided by the National Population Commission (NPC) as a sampling frame (6).

The 2013 NDHS sample was selected using a stratified 2-stage cluster design consisting of 904 clusters contained in 372 urban and 532 rural areas. A total of 40680 households were contained in these cluster. In each state all households listed was distributed proportionately among its rural and urban areas (6). By equal probability systematic sampling in the second stage of the selection process, an average of 45 households was selected from each cluster. A total of 40320 households were selected from 896 sample points. From this 38904 households were found to be occupied at the time of the fieldwork. Of the occupied households, 38522 were successfully interviewed, providing a household response rate of $99 \%$.

The study eligibles were all women age 15-49 who were either permanent residents of the households in the 2013 NDHS sample or visitors present in the households on the night before the survey. Also, as subsample, 1 eligible woman in each household was randomly selected and asked additional questions on sensitive issues such as domestic violence and female circumcision. In all a total of 23815 eligible women were successfully interviewed for the female circumcision survey (6).

\section{Data Collection}

Data collection for the 2013 NDHS was carried out by 37 trained interviewing teams, one for each of the 36 states of the country and FCT. Each team consisted of a supervisor, 1 field editor, 2 male interviewers, 4 female interviewers, and 2 drivers. The technical team/trainers that also functioned as quality controllers ensured the data quality. Also through field check tables generated concurrently with data processing, data quality was monitored. Due to security reasons, data collection could not be completed in eight clusters: 4 in Borno, 2 in Yobe, 1 in Nasawara, and 1 in Plateau all in the North-east and North-central region (6).

Operational Definitions

Girl-child circumcision refers to a variety of procedures involving partial or total removal of the external genitalia of a female child (7). The female external genital organ consists of the vulva, which is comprised of the labia majora, labia minora, and the clitoris covered by its hood. In 2007 the WHO categorized FGM into (i) Type I or clitoridectomy which is partial or total removal of the clitoris and/or the clitoral hood, (ii) Type II or excision refers to partial or total removal of the clitoris and the labia minora, with or without excision of the labia majora, (iii) Type III or infibulation is the narrowing of the vaginal orifice with creation of a covering seal by cutting and placing together the labia minora and/or the labia majora, with or without excision of the clitoris, and (iv) Type IV or unclassified is all other harmful procedures to the female genitalia for nonmedical purposes eg, pricking, piercing, incising, scraping, and cauterization (7). In this study, respondents were categorized into those who circumcised at least one of their female children for non medical reasons and those who did not circumcise any of their girl children.

\section{Sociodemographic Characteristics} Maternal Factors

(i) Age of respondent: was assessed in years and grouped as 15-24, 25-34, 35+; (ii) Educational attainment: was assessed as highest level of education and grouped into no education, primary and secondary or higher education; (iii) Marital status: of the surveyed women was originally grouped as "never married," "currently married," "formerly married." These were recoded into currently married for mothers in marriage and not married for mothers who have never and/or formerly married groups; (iv) Living with husband: was created by categorizing those currently married as those living with their spouse and those who are not; $(v)$ Contributes to family decision: was assessed by asking if the women had final say regarding significant household activities. Possible response options "respondent alone," "respondent and husband/partner," "respondent and other person in the household," formed one group of the dichotomy, while the options "husband/partner alone," and "someone else" formed the other group of the dichotomy. The various answers within each subvariable were all summed up and categorized as 'no' for women with no decision autonomy and 'yes' for those who had autonomy in family decisions; (vi) Access to electronic or print media: was assessed using question on frequency of listening to radio, reading newspapers/magazines, and watching television. Possible responses were not all, less than once a week, at least once a week and almost every day. The responses were dichotomized and summed up into "No" for those with no access (not at all and less than once a week), and "Yes" for women who had access (at least once a week and almost every day) to print and electronic media; (vii) Opinion on female circumcision: was constructed by grouping respondents into those who believe female circumcision is right and/or unharmful and should continue; those who think it is harmful and should stop and those who think female circumcision practice depends on some nonmedical extraneous factors; (viii) 
Mother circumcision: was classified as respondents who were circumcised as children or adults and those who were not; (ix) Place of child birth: was grouped into "institutional" for respondents who delivered in institutional facilities (ie, hospital, health centres etc) and "noninstitutional" for those who had their deliveries in nonhealth institution (ie, TBA, home deliveries, etc); and ( $x$ ) Postnatal check-up visit: was classified as "institutional" for respondents who used the health facilities for postnatal check-up for their newborn babies and "noninstitutional" for those whose postnatal check-up was not in a health facility.

\section{Paternal factors}

These respondents husbands variables were classified as: (i) Husband's age: in years was categorized as 16-24, 25-34 and 35+, and (ii) Husband's educational attainment: was also categorized as none for men without any formal education, primary (basic education), secondary, and higher (postprimary and/or college, polytechnic or university education).

Household factors

(i) Sex of households head: categorized as male and female; (ii) Household wealth index: defined as the wealth status of a households and categorized as poor, middle and rich class; (iii) Household educational inequalities: defined as the differences in educational attainment in years between respondent and her spouse/partner and categorized as "same education as husband/partner," "more educated than husband/partner," and "respondent is less educated than partner"; (iv) Household earning inequalities: defined as the differences in income or earnings between respondent and her spouse/partner and categorized as "earns the same as husband/partner," "earns more than husband/ partner," and "respondent earns less than husband/partner"; ( v) Household location: defined as the geographic location of the household and categorized as urban and rural; (vi) Household region of residence: defined as household location based on the 6 geopolitical zones in Nigeria and categorized as: North-central, North-east, Northwest, South-east, South-west and South-south; and (vii) Household religion: was categorized into Christianity, Islam and traditional religion.
Ethical Considerations and Data Analysis

The survey procedure and instruments for DHS for Nigeria was ethically approved by the Ethics Committee of the Opinion Research Corporation (ORC) Macro International Inc, Calverton, USA, and by the National Ethics Committee of the Federal Ministry of Health of Nigeria. Informed consent was obtained from all participants prior to participation in the survey, and collection of information was confidential. This study is based on analysis of secondary data with all participant identifiers removed. Ethical permission for use of the data in the present study was obtained from ORC Macro Inc. (6).

The Predictive Analytics Software (PASW) version 20.0 was used for data analysis. Multivariate logistic regression was used to predict the relationship between practice of girl child circumcision and sociodemographic variables. Results were presented in percentages, odds ratios and 95\% confidence intervals where appropriate. Statistical significance was set at $P<.05$.

\section{Results}

Characteristics of Respondents

A total of 39104 women from 38522 household were successfully interviewed across the 37 states in the 2013 Nigeria demographic and health survey. Of this, 23815 respondents consented and completed the girl child circumcision questionnaire giving a recruitment fraction of $60.9 \%$. Tables 1 and 2 show the summary statistics of the women that participated in the survey.

\section{Girl-Child Circumcision Practice}

All respondents surveyed were aware and had heard of female circumcision. Circumcision of the girl child was practiced by 5693 (23.9\%) of the 23815 respondents. Majority $5233(91.9 \%)$ of the girls were circumcised at ages between $0-11$ months and the remaining 330 (5.8\%) and 130 (2.3\%) were circumcised at $1-5$ and $\geq 6$ years, respectively. Circumcision was performed by traditional circumcisers in $84.6 \%(4725 / 5693)$ and health professional in $15.4 \%(861 / 5693)$ of these children. Type I (44.1\%) and II (47.9\%) were the commonest genital mutilation procedure performed while type III (4.0\%) and type IV (3.9\%)

Table 1. Summary Statistics of Respondents

\begin{tabular}{lcc}
\hline Variable, ( $\mathbf{N}=\mathbf{2 3 8 1 5}$ ) & Mean \pm Standard, Deviation (max, min) & Standard Error \\
\hline Number of respondents (per state) & $643.7 . \pm 78.3(2246,61)$ & 5.060 \\
Age of respondents & $35.9 \pm 8.1(49,15)$ & 0.002 \\
Respondents years of education & $4.8 \pm 1.6(17,0)$ & 0.015 \\
Age of husband & $46.5 \pm 11.0(95,16)$ & 0.003 \\
Husbands years of education & $5.7 \pm 1.4(20,0)$ & 0.002 \\
Number of living children & $4.8 \pm 2.2(16,0)$ & 0.006 \\
Number of daughters & $2.6 \pm 1.4(9,1)$ & 0.004 \\
Number of daughters circumcised & $1.8 \pm 1.0(5,1)$ & 0.007 \\
Age at daughters circumcision (years) & $0.2 \pm 1.1(15,0)$ \\
\hline
\end{tabular}

a Respondents that circumcised at least one girl-child. 
Table 2. Respondents Region and State of Residence

\begin{tabular}{|c|c|c|c|c|c|}
\hline \multirow{3}{*}{ Region } & \multirow{3}{*}{ States of Residence } & \multirow{2}{*}{ Respondents } & \multicolumn{2}{|c|}{ Residential Area } & \multirow{2}{*}{ Prevalence of FGM } \\
\hline & & & Urban & Rural & \\
\hline & & No. (\%) & No. (\%) & No. (\%) & No. (\%) \\
\hline \multirow[t]{7}{*}{ North-central } & Abuja (FCT) & $285(1.2)$ & $191(67.0)$ & $94(33.0)$ & $6(2.1)$ \\
\hline & Benue & $283(1.2)$ & $57(20.1)$ & 226 (79.9) & 11 (3.9) \\
\hline & Kogi & $145(0.6)$ & $56(38.6)$ & $89(61.4)$ & $5(3.4)$ \\
\hline & Kwara & $714(3.0)$ & $491(68.8)$ & $223(31.2)$ & $239(33.5)$ \\
\hline & Nasawara & $254(1.1)$ & $30(11.8)$ & $224(88.2)$ & 20 (7.9) \\
\hline & Niger & $198(0.8)$ & $56(28.3)$ & $142(71.7)$ & $19(9.6)$ \\
\hline & Plateau & $61(0.3)$ & $34(55.7)$ & $27(44.3)$ & $2(3.3)$ \\
\hline \multirow[t]{6}{*}{ North-east } & Adamawa & $294(1.3)$ & $108(36.7)$ & $186(63.3)$ & $2(0.7)$ \\
\hline & Bauchi & $610(2.6)$ & $126(20.7)$ & $484(79.3)$ & $150(24.6)$ \\
\hline & Borno & $478(2.0)$ & $192(40.2)$ & $286(59.8)$ & $21(4.4)$ \\
\hline & Gombe & $475(2.0)$ & $94(19.8)$ & $381(80.2)$ & $11(2.3)$ \\
\hline & Taraba & $748(3.2)$ & $129(17.2)$ & $619(82.8)$ & $92(12.3)$ \\
\hline & Yobe & $1041(4.4)$ & $305(29.3)$ & 736 (70.7) & $54(5.2)$ \\
\hline \multirow[t]{7}{*}{ North-west } & Jigawa & $1139(4.8)$ & $81(7.1)$ & 1058 (92.9) & 680 (57.9) \\
\hline & Kaduna & $664(2.8)$ & 258 (38.9) & 406 (61.1) & 338 (50.9) \\
\hline & Kano & 2446 (10.4) & 873 (35.7) & $1573(64.3)$ & 1171 (47.9) \\
\hline & Katsina & 725 (3.1) & $149(20.6)$ & $576(79.4)$ & $0(0.0)$ \\
\hline & Kebbi & $579(2.5)$ & $94(16.2)$ & 485 (83.8) & 55 (9.5) \\
\hline & Sokoto & $1369(5.8)$ & 263 (19.2) & $1106(80.8)$ & $359(26.2)$ \\
\hline & Zamfara & 1164 (4.9) & $190(16.3)$ & 974 (83.7) & $373(32.0)$ \\
\hline \multirow[t]{5}{*}{ South-east } & Abia & $521(2.2)$ & 119 (22.8) & $402(77.2)$ & $86(16.5)$ \\
\hline & Anambra & 441 (1.9) & $383(86.8)$ & $58(13.2)$ & $53(12.0)$ \\
\hline & Ebonyi & $784(3.3)$ & $678(86.5)$ & $106(13.5)$ & $199(25.4)$ \\
\hline & Enugu & $532(2.3)$ & $383(72.0)$ & 149 (28.0) & $123(23.1)$ \\
\hline & Imo & $480(2.0)$ & $217(45.2)$ & $263(54.8)$ & $165(34.4)$ \\
\hline \multirow[t]{6}{*}{ South-west } & Ekiti & $574(2.4)$ & $408(71.1)$ & 166 (28.9) & $286(49.8)$ \\
\hline & Lagos & $943(4.0)$ & $943(100.0)$ & $0(0.0)$ & $114(12.1)$ \\
\hline & Ogun & 354 (1.5) & 209 (59.0) & 145 (41.0) & $12(3.4)$ \\
\hline & Ondo & $563(2.4)$ & $270(48.0)$ & 293 (52.0) & $200(35.5)$ \\
\hline & Osun & 695 (2.9) & $502(72.2)$ & $193(27.8)$ & $258(37.1)$ \\
\hline & Oyo & $681(2.8)$ & 467 (68.6) & 214 (31.4) & $302(44.3)$ \\
\hline \multirow[t]{6}{*}{ South-south } & Akwa-Ibom & $416(1.8)$ & $17(4.1)$ & 399 (95.9) & $8(1.9)$ \\
\hline & Bayelsa & 745 (3.2) & $160(21.5)$ & 585 (78.5) & $10(1.3)$ \\
\hline & Cross-River & $564(2.4)$ & $62(11.0)$ & $502(89.0)$ & $18(3.2)$ \\
\hline & Delta & $667(2.8)$ & $299(44.8)$ & $368(55.2)$ & $68(10.2)$ \\
\hline & Edo & $711(3.0)$ & 397 (55.8) & $314(44.2)$ & $157(22.1)$ \\
\hline & Rivers & $472(2.0)$ & 197 (41.7) & 275 (58.3) & $26(5.5)$ \\
\hline Total & All states & $23815(100)$ & 9488 (39.2) & $14327(60.8)$ & 5693 (23.9) \\
\hline
\end{tabular}

were less practiced.

Within religious sects, prevalence rate of girl child circumcision was almost twice among Muslim respondents than those practicing other religions (Muslims 4032 [30.5\%] vs Christians 1598 [15.5\%] vs traditionalists 42 [19.2\%]; $P=.001)$. More Muslims compared to Christian respondents believed in religious justification of female circumcision $(24.3 \%$ vs $11.2 \%$; $P=.001)$. There was a wide prevalence rate range of FGM between regions 8.0\%-36.5\% (Figure 1) and States 0\%-57.9\% (Table 2). Among tribes, the highest prevalence was seen among Yorubas (36.6\%), Hausas (33.2\%) and, Fulanis (30.8\%) and the lowest prevalence was among Ijaws $(1.0 \%)$, Tiv (1.2\%), and Nupe (2.0\%). Others include Ibos (21.1\%), Fulfudes (17.9\%), Kanuris (8.0\%), Urhobos (5.6\%), Ebiras (5.5\%), and Ibibios $(3.6 \%)$. The other sociodemographic factors that are significantly associated with circumcision of the girl child amongst respondents are shown in Table 3. Logistic regression analysis in the first model showed that respondents educational attainment, access to media, opinion on
FGM, whether respondents was circumcised and use of health facility during child birth significantly predicted

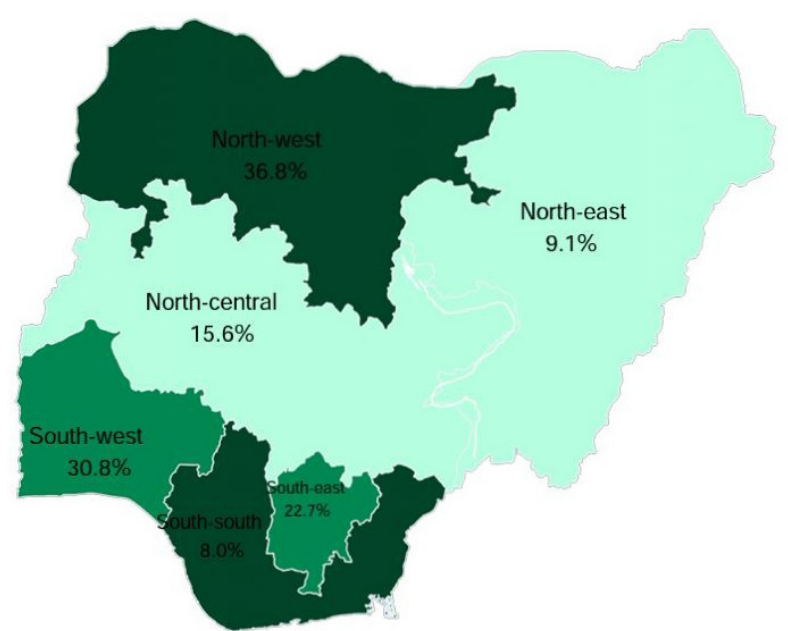

Figure 1. Prevalence of FGM Among Respondents in Different Regions of Nigeria. 
Table 3. Association Between Sociodemographic Factors and Girl Child Circumcision

\begin{tabular}{|c|c|c|c|c|}
\hline \multirow{2}{*}{ Sociodemographic Factors } & \multirow{2}{*}{ No. (\%) } & \multicolumn{2}{|c|}{ Girl Child Circumcised, No. (\%) } & \multirow{2}{*}{ P-Value } \\
\hline & & No & Yes & \\
\hline \multicolumn{5}{|c|}{ Level 1: Maternal Variables } \\
\hline \multicolumn{5}{|l|}{ Age of mother (years) } \\
\hline $15-24$ & $2369(9.9)$ & $1772(9.8)$ & $597(10.5)$ & .261 \\
\hline $25-34$ & $4782(20.1)$ & $3659(20.2)$ & $1123(19.7)$ & \\
\hline $35+$ & $16664(70.0)$ & $12691(70.0)$ & $3973(69.8)$ & \\
\hline \multicolumn{5}{|c|}{ Educational attainment of mother } \\
\hline None & $10317(43.3)$ & $7272(40.1)$ & 3045 (53.5) & .001 \\
\hline Primary & $11717(49.2)$ & $9276(51.2)$ & 2441 (42.9) & \\
\hline Secondary or higher & $1781(7.5)$ & $1574(8.7)$ & $207(3.60$ & \\
\hline \multicolumn{5}{|l|}{ Marital status } \\
\hline Not married & $1416(5.9)$ & $1155(6.4)$ & $261(4.6)$ & .001 \\
\hline Currently married & $22399(94.1)$ & $16967(93.6)$ & $5432(95.4)$ & \\
\hline \multicolumn{5}{|l|}{ Living with husband } \\
\hline No & $2204(9.9)$ & $1717(10.2)$ & $487(9.0)$ & .013 \\
\hline Yes & $16884(90.1)$ & $15167(89.8)$ & 4921 (91.0) & \\
\hline \multicolumn{5}{|l|}{ Contributes to family decisions } \\
\hline No & $766(4.8)$ & $120(2.9)$ & $646(5.4)$ & .001 \\
\hline Yes & $15320(95.2)$ & $3963(97.1)$ & $11357(94.6)$ & \\
\hline \multicolumn{5}{|c|}{ Access to electronic or print media } \\
\hline No & $12160(54.4)$ & $9014(53.4)$ & $3146(57.2)$ & .001 \\
\hline Yes & $10211(45.6)$ & $7855(46.6)$ & $2356(42.8)$ & \\
\hline \multicolumn{5}{|l|}{ Opinion on female circumcision } \\
\hline To continue & $5720(24.8)$ & $2223(12.7)$ & $3497(62.6)$ & .001 \\
\hline To stop & $15166(65.7)$ & $13632(77.9)$ & $1534(27.5)$ & \\
\hline Conditional & $2193(9.5)$ & $1642(9.4)$ & 551 (9.9) & \\
\hline \multicolumn{5}{|l|}{ Mother circumcised } \\
\hline No & $13342(59.7)$ & $12272(71.5)$ & $1070(20.6)$ & .001 \\
\hline Yes & $8996(40.3)$ & $4882(28.5)$ & $4114(79.4)$ & \\
\hline \multicolumn{5}{|l|}{ Place of child birth } \\
\hline Non institutional & $5463(59.3)$ & $4074(57.0)$ & $1389(67.3)$ & .001 \\
\hline Institutional & $3753(40.7)$ & $3079(43.0)$ & $674(32.7)$ & \\
\hline \multicolumn{5}{|l|}{ Postnatal check-up visit } \\
\hline Non institutional & $221(11.8)$ & $163(10.5)$ & $58(17.7)$ & .001 \\
\hline Institutional & $1659(88.2)$ & $1389(89.5)$ & $270(82.3)$ & \\
\hline \multicolumn{5}{|c|}{ Level 2: Paternal Variables } \\
\hline \multicolumn{5}{|l|}{ Age of husband } \\
\hline $16-24$ & $136(0.6)$ & $114(0.7)$ & $22(0.4)$ & .012 \\
\hline $25-34$ & $3276(14.6)$ & 2525 (14.9) & $751(13.8)$ & \\
\hline $35+$ & $18987(84.8)$ & $14328(84.4)$ & $4659(85.8)$ & \\
\hline Educational attainment of hu & & & & \\
\hline None & $8386(35.9)$ & 5834 (32.9) & $2552(45.4)$ & .001 \\
\hline Primary & $4950(21.2)$ & $3738(21.1)$ & $1212(21.6)$ & \\
\hline Secondary or Higher & $10036(42.9)$ & $8177(46.1)$ & $1859(33.1)$ & \\
\hline & Level 3: House & Variables & & \\
\hline Sex of household head & & & & \\
\hline Male & $20680(86.8)$ & $15646(86.3)$ & $5034(88.4)$ & .001 \\
\hline Female & 3135 (13.2) & $2476(13.7)$ & $659(11.6)$ & \\
\hline Household wealth index & & & & \\
\hline Poor & $9556(40.1)$ & $6716(37.1)$ & $2840(49.9)$ & .001 \\
\hline Middle & $4584(19.2)$ & 3575 (19.7) & $1009(17.7)$ & \\
\hline Rich & $9675(40.6)$ & $7831(43.2)$ & $1844(32.4)$ & \\
\hline Household educational inequ & & & & \\
\hline Same level & $5754(47.5)$ & $4623(47.2)$ & $1131(49.1)$ & .070 \\
\hline Wife more educated & $2733(22.6)$ & $2204(22.5)$ & $529(23.0)$ & \\
\hline Husband more educated & 3616 (29.9) & $2973(30.3)$ & $643(27.9)$ & \\
\hline Household earning inequaliti & & & & \\
\hline Same earnings & $934(5.9)$ & $699(6.0)$ & $235(5.9)$ & .001 \\
\hline Wife earns more & $781(5.0)$ & $659(5.6)$ & $122(3.0)$ & \\
\hline
\end{tabular}

146 | International Journal of Women's Health and Reproduction Sciences, Vol. 3, No. 3, July 2015 


\begin{tabular}{|c|c|c|c|c|}
\hline Husband earns more & $14033(89.1)$ & $10373(88.4)$ & $3660(91.1)$ & \\
\hline \multicolumn{5}{|l|}{ Household location } \\
\hline Urban & $9488(39.8)$ & $7142(40.9)$ & $2076(36.5)$ & \multirow[t]{2}{*}{.001} \\
\hline Rural & $14327(60.2)$ & $10710(59.1)$ & $3617(63.5)$ & \\
\hline \multicolumn{5}{|c|}{ Household region of residence } \\
\hline North-Central & $1940(8.1)$ & $1638(9.0)$ & $302(5.3)$ & \multirow[t]{6}{*}{.001} \\
\hline North-East & $3646(15.3)$ & $3316(18.3)$ & $330(5.8)$ & \\
\hline North-West & $8086(34.0)$ & $5110(28.2)$ & $2976(52.3)$ & \\
\hline South-East & $2758(11.6)$ & $2132(11.8)$ & $626(11.0)$ & \\
\hline South-West & $3810(16.0)$ & $2638(14.6)$ & $1172(20.6)$ & \\
\hline South-South & $3575(15.0)$ & $3288(18.1)$ & $287(5.0)$ & \\
\hline \multicolumn{5}{|l|}{ Household religion } \\
\hline Christianity & $10278(43.3)$ & $8680(48.1)$ & $1598(28.2)$ & \multirow[t]{2}{*}{.001} \\
\hline $\begin{array}{l}\text { Islam } \\
\text { Traditional }\end{array}$ & $\begin{array}{c}13212(55.7) \\
219(1.0)\end{array}$ & $\begin{array}{c}9180(50.9) \\
177(1.0)\end{array}$ & $\begin{array}{c}4032(71.1) \\
42(0.7)\end{array}$ & \\
\hline
\end{tabular}

Abbreviation: FGM, female genital mutilation.

the likelihood of girl child circumcision. After fitting in paternal factors in model 2, these factors maintained their significance. In the third model, following adjustment for household variables only respondent's opinion on FGM and whether she was circumcised retained significance while region of residence became and also retained significance in the final model (Table 4).

Respondents who believe that the practice of female circumcision was harmful and should be stopped were 0.02 times less likely to circumcise their girl child $(\mathrm{OR}=0.02$; 95\% CI: 0.01-0.04) compared to respondents who believe that female circumcision should continue. In other words those who believe female circumcision is unharmful and should continue are fifty times more likely to circumcise their girl child. Similarly, women who think the practice of female circumcision is dependent on some extraneous factors had 0.16 times less likelihood to engage in the practice ( $\mathrm{OR}=0.16 ; 95 \% \mathrm{CI}: 0.06-0.40)$ compared to respondents who think it should continue. Furthermore, respondents who were circumcised as children or adults had about 6.6 times more likelihood to circumcise their own daughters compared to respondents who were not circumcised $(\mathrm{OR}=6.60$; $95 \%$ CI: 2.82-15.48). Finally, respondent residing in the North-central ( $\mathrm{OR}=0.57 ; 95 \%$ CI: 0.22-1.45), North-east (OR=0.52; 95\% CI: 0.97-2.74), South-east $(\mathrm{OR}=0.75 ; 95 \% \mathrm{CI}$ : 0.28-1.99) and South-west $(\mathrm{OR}=0.15 ; 95 \% \mathrm{CI}: 0.36-0.65)$ regions were less likely to circumcise their girl child while those in the North-west region $(\mathrm{OR}=2.20 ; 95 \% \mathrm{CI}: 0.61-7.82)$ were more likely to circumcise their girl child compared to respondents in the South-south region of Nigeria (Table 4).

\section{Discussion}

The prevalence of the practice of FGM in the girl child among respondents seen in this study (23.9\%) have shown little or no improvement compared to prevalence rate (25\%-40.1\%) reported by The United Nations Children's Fund (UNICEF) and NDHS 10 years ago in a similar survey (8). This is particularly disturbing in Nigeria whose 2006 population had females and girls $0-19$ years account- ing for $49.2 \%$ and $25.4 \%$ of its population, respectively (9). Similar population based data from other countries in sub-Saharan Africa with almost similar demographics as Nigeria has shown a significant decrease over the years following intensive campaign and female education on the complications of FGM. For instance Cote-d'Ivoire and the Central African Republic recorded a significant decrease in prevalence of FGM over the past 5-10 years from 45\% to $36 \%$ between 1999 and 2006 and $36 \%$ to $26 \%$ between 2000 and 2008, respectively (2). It is logical to assume that intensive campaign and education of women and the girl child on the ill health effect of FGM can drastically reduce its practice in Nigeria.

This assertion is further supported by the findings in this study which revealed that maternal opinion and having been a victim of genital mutilation is an important predictor of circumcision of the girl child after taking into account paternal and household factors considered in this study. A similar study in Ethiopia also showed that circumcised women were three times more likely to support continuation of circumcision (10). Unlike this study, a study in south-west Nigeria showed that education, place of residence, religion and level of awareness was significantly associated with FGM (11). This difference may be related to the multilevel adjusting of variables which was done in this study.

Region of household residence was also seen as a significant predictor of FGM even though its effect was not as consistent as the maternal factors. The regional effect could be attributed to cultural differences in the 6 regions of Nigeria. Cultural and traditional beliefs are well known to be the basis of many unpleasant maternal and child health practices in many communities within Africa $(12,13)$. Though many of these beliefs are commonly upheld and enforced by older members of the community, their effects still ripple among children of the younger generation. One way to get around this is by instituting effective community surveillance and deterrent laws enforced by head of communities against circumcisers, households and individuals that practice or promote the 
Table 4. Odds Ratio and 95\% Cl for Logistic Regression Models

\begin{tabular}{|c|c|c|c|}
\hline \multirow{2}{*}{ Sociodemographic Factors } & \multicolumn{3}{|c|}{ Odds Ratio (95\% Cl) } \\
\hline & Level 1 & Level 2 & Level 3 \\
\hline \multicolumn{4}{|l|}{ Age of mother (years) } \\
\hline $15-24$ & $0.78(0.41-1.52)$ & $0.66(0.31-1.44)$ & $0.37(0.12-1.08)$ \\
\hline $25-34$ & $1.26(0.78-2.03)$ & $1.18(0.70-2.00)$ & $0.83(0.42-1.66)$ \\
\hline $35+$ & 1 & 1 & 1 \\
\hline \multicolumn{4}{|c|}{ Educational attainment of mother } \\
\hline None & 1 & 1 & 1 \\
\hline Primary & $0.31(0.17-0.55)^{a}$ & $0.44(0.23-0.87)^{a}$ & $1.62(0.68-3.91)$ \\
\hline Secondary or Higher & $0.45(0.19-1.08)$ & $0.66(0.25-1.73)$ & $0.41(0.11-2.31)$ \\
\hline \multicolumn{4}{|l|}{ Living with husband } \\
\hline No & $1.18(0.65-2.15)$ & $1.20(0.66-2.21)$ & $2.01(0.59-6.85)$ \\
\hline Yes & 1 & 1 & 1 \\
\hline \multicolumn{4}{|c|}{ Contributes to family decisions } \\
\hline No & $0.65(0.15-2.82)$ & $0.68(0.15-2.96)$ & $1.03(0.10-10.54)$ \\
\hline Yes & 1 & 1 & 1 \\
\hline \multicolumn{4}{|c|}{ Access to electronic or print media } \\
\hline No & 1 & 1 & 1 \\
\hline Yes & $0.64(0.42-0.99)^{a}$ & $0.63(0.41-0.98)^{\mathrm{a}}$ & $0.63(0.33-1.18)$ \\
\hline \multicolumn{4}{|c|}{ Opinion on female circumcision } \\
\hline To continue & 1 & 1 & 1 \\
\hline To stop & $0.04(0.03-0.06)^{\mathrm{a}}$ & $0.04(0.02-0.06)^{\mathrm{a}}$ & $0.02(0.01-0.04)^{a}$ \\
\hline Conditional & $0.21(0.11-0.39)^{\mathrm{a}}$ & $0.19(0.10-0.38)^{\mathrm{a}}$ & $0.16(0.06-0.40)^{\mathrm{a}}$ \\
\hline \multicolumn{4}{|l|}{ Mother circumcised } \\
\hline No & 1 & 1 & 1 \\
\hline Yes & $6.40(3.74-10.91)^{\mathrm{a}}$ & $6.60(3.81-11.45)^{a}$ & $6.60(2.82-15.48)^{\mathrm{a}}$ \\
\hline \multicolumn{4}{|l|}{ Place of child birth } \\
\hline Non institutional & 1 & 1 & 1 \\
\hline Institutional & $0.53(0.32-0.89)^{\mathrm{a}}$ & $0.54(0.32-0.91)^{a}$ & $0.94(0.46-1.94)$ \\
\hline \multicolumn{4}{|l|}{ Postnatal check-up visit } \\
\hline Non institutional & 1 & 1 & 1 \\
\hline Institutional & $0.68(0.33-1.42)$ & $0.68(0.33-1.44)$ & $0.60(0.15-2.41)$ \\
\hline \multicolumn{4}{|l|}{ Age of Father } \\
\hline $16-24$ & & $0.00(0.00-0.00)$ & $0.00(0.00-0.00)$ \\
\hline $25-34$ & & $1.32(0.73-2.40)$ & $1.76(0.80-3.84)$ \\
\hline $35+$ & & 1 & 1 \\
\hline \multicolumn{4}{|c|}{ Educational attainment of father } \\
\hline None & & $2.21(1.05-4.66)$ & $0.98(0.49-1.95)$ \\
\hline Primary & & $0.96(0.57-01.63)$ & $0.46(0.27-1.83)$ \\
\hline Secondary or higher & & 1 & 1 \\
\hline \multicolumn{4}{|l|}{ Sex of household head } \\
\hline Male & & & 1 \\
\hline Female & & & $0.82(0.23-2.94)$ \\
\hline \multicolumn{4}{|l|}{ Household wealth index } \\
\hline Poor & & & $1.46(0.45-4.75)$ \\
\hline Middle & & & $1.19(0.53-2.68)$ \\
\hline Rich & & & 1 \\
\hline \multicolumn{4}{|c|}{ Household educational inequalities } \\
\hline Same level & & & 1 \\
\hline Wife more educated & & & $1.40(0.72-2.75)$ \\
\hline Husband more educated & & & $0.89(0.45-1.76)$ \\
\hline \multicolumn{4}{|l|}{ Household earning inequalities } \\
\hline Same earnings & & & $1.09(0.19-6.22)$ \\
\hline Wife earns more & & & $1.68(0.24-11.6)$ \\
\hline
\end{tabular}

148 | International Journal of Women's Health and Reproduction Sciences, Vol. 3, No. 3, July 2015 
Table 4. Continued

\begin{tabular}{|c|c|}
\hline Husband earns more & 1 \\
\hline \multicolumn{2}{|l|}{ Household location } \\
\hline Urban & $0.82(0.43-1.58)$ \\
\hline Rural & 1 \\
\hline \multicolumn{2}{|c|}{ Household region of residence } \\
\hline North-Central & $0.57(0.22-1.45)$ \\
\hline North-East & $0.52(0.97-2.74)$ \\
\hline North-West & $2.20(0.61-7.82)$ \\
\hline South-East & $0.75(0.28-1.99)$ \\
\hline South-West & $0.15(0.36-0.65)^{\mathrm{a}}$ \\
\hline South-South & 1 \\
\hline \multicolumn{2}{|l|}{ Household religion } \\
\hline Christianity & 1 \\
\hline Islam & $1.15(0.62-2.14)$ \\
\hline Traditional & $0.00(0.00-0.00)$ \\
\hline
\end{tabular}

a Statistically significant.

practice of FGM. Traditional circumcisers known (14) and seen in this study to be the main perpetuators of FGM was corroborated by similar finding in Eastern Ethiopia where $81 \%$ of circumcision in Somali refugees was performed by traditional circumcisers (15). This group of circumcisers should be particularly targeted using comprehensive educational programs in order to reduce or stop this atrocious act against women in general and the girl child in particular.

\section{Conclusion}

There is need for concerted effort by the government through the Ministries of Health, Information and Women affair in collaboration with the local government to institute extensive campaign involving community head, religious leaders and influential personalities in the community in addition to community residents and volunteers to engage in public enlightenment programs and effective surveillance in order to curtail or eradicate this negative and harmful practice of female circumcision.

\section{Ethical Issues}

This study was conducted using secondary data from the 2013 Nigeria demographic and health survey (DHS) for which prior ethical clearance have been obtained.

\section{Financial Support}

The author received no financial support for the research, authorship and/or publication of this article.

\section{Conflict of Interests}

The author declares no conflict of interests.

\section{Acknowledgments}

The author would like to thank the officials of the Opinion research company (ORC) owners of the Demographic and health survey for their kind assistance for permission to use the 2013 NDHS and also the Nigeria Federal Ministry of Health and NPC for their ethical clearance. The contents of this study are solely responsibility of the author and are in no way representative of the official views of the ORC. No competing interests is declared.

\section{References}

1. UNICEF in Action. Nigeria: Female genital Mutilation. http:/www.unicef.org. Accessed November 24, 2014.

2. Feldman-Jacobs C and Clifton D. Female Genital Mutilation/Cutting: Data and Trends. Population Reference Bureau updates; 2010.

3. World Health Organization (WHO). Female Genital Mutilation Fact Sheet No. 241. Geneva: WHO; 2008.

4. Okeke LI, Asinobi AA, Ikuerowo OS. Epidemiology of complications of male circumcision in Ibadan, Nigeria. BMC Urol. 2006;6:21. doi:10.1186-14712490-6-21.

5. People and Ethnic groups: CIA World fact book. http://www.cia.gov/library/publication/the-worldfactbook/geos/ni.html. Accessed November 24, 2014.

6. Nigeria Demographic and Health Survey 2013 Preliminary Report. Measure DHS ICF International Calverton, Maryland, USA and National Population Commission, Abuja, Nigeria; 2013.

7. World Health Organization (WHO). Eliminating Female Genital Mutilation: An Interagency Statement. Geneva: WHO; 2008.

8. Overview of Female Genital Mutilation/Cutting: Nigeria FGM/C country profile. UNICEF, Nigeria DHS 1999, 2003.

9. National Population Commission. Population distribution by age \& sex (state \& local government area); 2006 Population and Housing census priority table. Official gazette of the Federal Republic of Nigeria; 2010.

10. Masho SW, Matthews L. Factors determining whether Ethiopian women support continuation of female genital mutilation. Int J Gynecol Obstet. 
2009;107(3):232-235. doi:10.1016-2009.07.033.

11. Adeyemo AR, Omisore AO, Oladipupo A. Knowledge and practice of female circumcision among women of reproductive ages in South West Nigeria. J Humanities Social Sci. 2012;2(3); 38-45. doi: 10.97900837-0233845.

12. Furnham A, Akande D, Baguma P. Beliefs about health and illness in three countries: Britain, South Africa and Uganda. Psychol Health Med. 1999;4(2):189-201. doi:10.1080-135485099106324.

13. Kleinman A. Concepts and a model of the comparison of medical systems as cultural systems. In: Currer
C, Stacey M, eds. Concepts of Health, Illness, and Handicap. Geneva: Harwood Academic Publishers; 1986.

14. Garcia-Moreno C, Guedes A, Knerr W. Understanding and addressing violence against women: Female genital mutilation. Geneva: World Health Organization; 2012

15. Mitike G, Deressa W. Prevalence and associated factors of female genital mutilation among Somali refugees in eastern Ethiopia: a cross-sectional study. BMC Public Health. 2009;9:264. doi:10.1186/14712458-9-264.

Copyright $(2015$ The Author(s); This is an open-access article distributed under the terms of the Creative Commons Attribution License (http://creativecommons.org/licenses/by/4.0), which permits unrestricted use, distribution, and reproduction in any medium, provided the original work is properly cited. 